\title{
A Review on the Role of Veterinary Public Health and Its Current Challenges
}

\author{
${ }^{\text {"Tamirat Kaba }}{ }^{1}$, Tesfahiwot Zerihun ${ }^{1}$, Berhanu Abera ${ }^{2}$, Temesgen Kassa ${ }^{2}$ \\ ${ }^{1}$ Haramaya University, College of Veterinary Medicine \\ ${ }^{2}$ Ethiopian Institute of Agricultural Research, Holleta Agricultural Research Center, Holleta, Ethiopia
}

"Corresponding author: Tamirat Kaba, Haramaya University, College of Veterinary Medicine, P.O. Box 138, Dire Dawa, Ethiopia; Email: tamirat11@gmail.com

Citation: Kaba T, Zerihun T, Abera B, Kassa T (2017) A Review on the Role of Veterinary Public Health and Its Current Challenges. Arch Vet Sci, 2017: VST-114. DOI:10.29011/AVST-114/100014

Received Date: 24 April, 2017; Accepted Date: 27 April, 2017; Published Date: 8 May, 2017

\begin{abstract}
Summary
The first section of this paper presents the role and activities of Veterinary Public Health (VPH) professionals at the international level regardless of the difference in VPH structure among the countries. The Second section briefly describes about the challenges that VPH has been facing and its future trends. Measures to safeguard human health and control of disease in livestock and other animals for the prevention of the transmission of animal-borne or zoonotic diseases are too often undertaken in isolation of one another. The medical and veterinary professionals have traditionally focused respectively on the improvement of human health and livestock health and production as their primary objective respectively. It is this compartmentalization of the medical and veterinary sectors which underlies the "divided constituencies" which predominate, but which is less desirable in poor countries where the zoonotic disease burden is greatest. Zoonoses have direct impact on public health and livestock production and therefore should be a point of convergence for the two sectors providing an opportunity for "unified constituencies. An inextricable interconnection of humans, pets, livestock, wildlife and their ecological environment is evident and requires integrated approaches to human and animal health along with their respective social and environmental contexts. Significant changes in land use, expansion of large and intensified animalproduction units, and microbial and chemical pollution of land and water sources have created new threats to the health of both animals and humans. Together these have led to creation of a new scientific discipline called ecosystem health, and VPH staffs are assuming a leadership role in the field of ecosystem health. In this context, it's recommended that public health veterinarians (VPH), physicians, other health professionals and environmental health protection list must work in close collaboration to achieve one health goal.
\end{abstract}

Keywords: Environmental health, Food safety, Physician, VPH, Zoonoses

\section{Introduction}

According to World Health Organization (WHO), Veterinary Public Health (VPH) is a component of public heath activities devoted to the application of professional veterinary skills, knowledge and resource for protection and improvement of human health. However, the joint Food and Agricultural Organization (FAO)/WHO expert committee in 1999 [1] on VPH expanded this concept to "the sum of all contribution to physical, mental and social wellbeing of human through understanding and applica- tion of veterinary science. In order to achieve VPH objectives, the WHO experts stressed the need (i) for the establishment of a VPH unit staffed with public health veterinarians to deal primarily with the major VPH issues, such as zoonoses control and protection of foods of animal origin, (ii) for close collaboration between the different professional groups, especially between veterinarians, public health workers and environmental professionals which can contribute to the goal of VPH [2]. VPH comprises all the community efforts influencing and influenced by the veterinary medical arts and sciences applied to the prevention of diseases, protection of life, and promotion of the well being and efficiency of man, [3]. Human health is inextricably linked to animal health, this link 
between human and animal populations, and with the surrounding environment, is particularly close in developing regions where animals provide transportation, draught power, fuel and clothing as well as proteins such as meat, eggs and milk [4].

Historically, the veterinary services were just set up to control and prevent major epizootic livestock diseases at farm level [5]. This historical separation of veterinary and medical services in different departments between which there is no effective collaboration was due to lack of understanding of the veterinarian's potential contribution to community health care [6]. Most people were asked to consider what word they would associate with veterinarians. It was likely they associated it with cattle, equines, dogs, cats, and their health. Vets are not only trained to deal with all non human animals, but also they trained in an extremely wide set of disciplines, protecting public health is one of the area that vets involve. As country begins to bring serious disease under control the scope of official animal health service was normally increased to address public health problem originating from livestock and their products. The role of veterinary service was extended from farm to food processing plants, where veterinarians have dual responsibilities (surveillance of animal disease and implementation of safety of food of animal origin) Office of the International Epizooties [7]. Currently, the scope of VPH is clearly multidisciplinary, besides dealing with animal disease, it concerns about zoonoses, food born disease and environmental health [8]. VPH staffs are not just veterinarians, but also other health and agriculture professionals such as physicians, environmental protectionist, public health workers and others. Although the role and activities of VPH is multidisciplinary, the concept and practice of VPH in Africa is somewhat different and limited in terms of protection of human health according to the report described by the Joint Food and Agriculture Organization (FAO) and WHO Expert Committee in VPH [9].

A number of global changes will occur during the next 2530 years that will have a dramatic impact on most Professional groups, especially physicians and veterinarians that hinder them from reaching up to "one health" concept. A number of these changes are under way and their consequences are already apparent. To minimize the consequence, VPH staffs will adopt new strategies to reach up to health goal [10]. Therefore the objective of this review is to highlight: (i) the multidisciplinary activities of licensed public health veterinarians (ii) current challenges that VPH facing (iii) prospective of VPH

\section{The Role of Veterinary Public Health (Vph)}

VPH scope and structures vary from country to country in Africa [11]. For instance, four countries reported having a VPH structure within the Ministry of Agriculture, namely Burkina Faso, Eritrea, South Africa and Zimbabwe. In Burkina Faso, VPH is one of two subdivisions of the Animal Health Directorate and it's a branch to deal only with meat hygiene and dairy products for ex- port purpose. In Eritrea, Veterinary Services are part of the Animal Resources Department and are divided into two sections: Disease Prevention and Control, and VPH. In South Africa, VPH services fall under the National Department of Agriculture and mainly responsible for meat hygiene [12]. In Zimbabwe, a VPH branch exits in all abattoirs for export. Some countries such as Ghana, Mali and Botswana have been trying to bring collaboration of veterinary service with ministry of health and local municipality. In some African nations prevention of environmental risks in relation to the animal industry and derived pollutants is another scope of VPH (e.g. Kenya, Madagascar, Malawi and Morocco). In Ethiopia, according to the study conducted by [13], VPH activity focus only on meat hygiene for export purpose, but zoonoses control is very limited. Furthermore, there is no structural organization of veterinary public health units. While VPH scope and structure vary in different country, the existing fact has witnessed that the responsibilities of VPH staffs falls under the following activities at the international level [14].

\section{Zoonoses Control and Prevention}

The monitoring and control of the whole range of zoonoses and the wide spectrum of susceptible animal species is an enormous task of public health veterinarians [15]. Only estimates and fragments of information are available from the literature and data published by international organizations such as the FAO, OIE and WHO [15]. The term zoonoses is defined as, any disease which can be transmitted from animals to man under natural condition. About $75 \%$ of the new diseases that have affected humans over the past many years have been caused by pathogens originating from an animal or from products of animal origin. Many of these diseases have the potential to spread through various means over long distances and to become global problems. Zoonotic disease poses an important threat to human health and should therefore be taken as serious issue. The essential role of animals in the transmission of infectious diseases has long been recognized. Not only were animals known to be responsible for the maintenance of infections in nature by harboring and enabling pathogens to survive; but also found to be an active cause of pathogen spread in the environment and to other animals, including man [16]. The potential significance of zoonoses is often ignored by public health policy and limited resources are available to investigate them in many countries [17]. There are three main reasons why zoonoses need to be considered as serious threats to public health $[18,19]$.

Firstly, a disease that starts as a zoonosis may have the potential to develop into a major human communicable disease [20]. There is strong evidence to suggest that certain communicable disease of human example influenza and HIV originated from non human animas. Therefore, zoonoses must be considered seriously as possible future human communicable diseases, and ignoring them will pose a threat to public health [21]. Secondly, many zoonoses are able to cause very significant human morbidity and mortality. 
Amongst these are brucellosis, leptospirosis, anthrax, rabies salmonellosis, tuberculosis and echinococcosis, and a large number of other bacterial, viral and parasitic infections [22].

Thirdly, some zoonotic infections also cause serious disease in agricultural and food-producing animals. This can result in a reduced availability of animal-derived food and reduced wealth in animal-owning communities (Federation of Veterinarians in Europe (FVE) [23]. Moreover, some zoonotic diseases may impact food security by affecting the production and productivity of animals in terms of quality and/or quantity of meat, milk, eggs, and manure output and traction power, causing food insecurity which in turn results in starvation in livestock dependant community.

\section{Food Safety Implementation}

Food safety can be defined as all measures undertaken so that food will not cause disease or infection when it's eaten, implementation of the safety of food of animal origin is one of the discipline public health veterinarians involve $[24,25]$. Food safety and quality are best assured by an integrated, multidisciplinary approach, considering the whole food production chain. Eliminating or controlling food hazards at source, (a preventive approach), is more effective in reducing or eliminating the risk of unwanted health effects than, traditionally applied via a final 'quality check' approach [26]. Approaches to food safety have evolved in recent decades, from traditional controls base to more targeted food safety systems based on hazard analysis and critical control points (HACCP) to risk-based approaches using food safety risk analysis Codex Alimentary Commissions. HACCP is a preventive risk management approach that has been extensively used by food industries to increase product safety. There are two levels in which veterinarians go through and play a role to ensure the production of safe food of animal origin [27].

\section{At farm level}

The source of food animal is the major criteria and prerequisite for any food processing plant. In modern food producing company, food animals are usually obtained from well organized farms where contagious diseases are unlikely to occur. Through their presence in farms and appropriate collaboration with farmers and other professionals, vets play a key role in ensuring the production of healthy animals which fit for food [28].

\section{At food processing plant}

Slaughterhouse inspection of live animals (ante-mortem) and their carcasses (post-mortem) play a key role in both the surveillance network for animal diseases and zoonoses and ensuring the safety and suitability of meat and by-products for their intended uses. Most reported outbreaks of food borne disease are due to contamination of foods with zoonotic agents, often during primary production. Public health veterinarians play a key role in the investigation of such outbreaks all the way back to the farm and in formulating and implementing remedial measures once the source of the outbreak has been identified [29]. Another important Service is to ensure health certification for international trade. Certification in relation to animal diseases, including zoonoses, and meat hygiene should be the responsibility of the Veterinary Authority. Certification may be complies with animal health and food safety standards [30].

\section{Environmental Protection}

An inextricable interconnection of humans, pets, livestock, wildlife and their ecological environment is evident and requires integrated approaches to human and animal health along with their respective social and environmental contexts. Because veterinarians work at the interface of human, animal, and environmental health, they are uniquely positioned to view this dynamic through the lens of public health impact. Significant changes in land use, expansion of large and intensified animal-production units, and microbial and chemical pollution of land and water sources have created new threats to the health of both animals and humans [31]. Concerns are increasing about antimicrobial resistance of pathogens waste and nutrient management, and potential runoffs into streams, rivers, and oceans. Food animal and wildlife populations are inextricably linked to some environmental problems. Together these have led to creation of a new scientific discipline called ecosystem health, and veterinarians are assuming a leadership role in the field of ecosystem health. The essential definition of health can be applied to all animals, humans and environment. Environmental health then is a coherent field of responsibility for veterinary medicine like animal health and public health [32]. In the 20th century, Calvin Schwabe who was an American veterinary epidemiologist and parasitologist developed and promoted the concept of one medicine [33]. According to the concept, between animal and human medicine there were no dividing lines-"nor should there be". The concept did not consider environmental health in terms of both human and non human animals' health. Considering a broader approach to health and well-being of societies, the first concept of one medicine was extended to one health approach through practical implementations and careful validations in different settings [34]. One Health has been defined as the collaborative effort of multiple disciplines working locally, nationally, and globally to attain optimal health for people, animals and the environment [6].

\section{Challenges Facing Vph in 21th Century}

Public health veterinarians have been facing many challenges since several years ago. The daily interactions of humans, animals, and the environment have a dramatic impact on public health. Current and evolving health threats include infections transmitted through animals, insects, food, and water, as well as illnesses resulting from environmental toxins, the misuse of antibiotics, and bioterrorism. Factors affecting these threats include the international movement of people, animals, and animal products; globalization and man- 
agement of the complex food and fiber system; climate and other environmental changes, including those affecting wildlife populations and their interactions; and national and global security. The most important challenges are the followings [35].

\section{System of Livestock Production}

Changes in the system of livestock production from extensive (backyard) to intensive in aiming to produce adequate and safe food of animal origin widely practiced in several countries now days. Intensive animal farming practices can involve very large numbers of animals raised on limited land which requires large amounts of food, water and medical inputs (required to keep the animals healthy in cramped conditions). Unfortunately, the spread of contagious or zoonotic disease in the entire herd is likelihood if infection commence even in one animal [36].

\section{Antimicrobials Usage}

Drugs that improve the rate of weight gain, improve feed efficiency, or prevent and treat diseases in food-producing animals are critically needed to meet the challenge of providing adequate amounts of food for that population [37]. But, the benefit of improved production from the use of animal drugs in food producing species is not obtained without risk. The risk associated with drug residues that remain in the tissues of treated animals are usually detected in meat and milk. The common reason for the presence of drug residue in food of animal is failure to read recommended withdrawal period. The risk associated with chemical residue in food of animals to human health is not easy concern, public health hazard include, drug resistance, hypersensitivity reaction, teratogenic and carcinogenic effect [9].

\section{Welfare Issue}

It is often said that good animal welfare equates to good food safety. Public health, animal health and animal welfare are indeed interrelated and require a holistic approach. As an example of this, stressed animals are likely to develop diseases, which will require veterinary treatment. However, this may increase the presence of residues in the animal product, which in turn may enhance development of drug resistance in human [38].

\section{Globalization of Trade}

Globalization of trade has facilitated the spread of food borne infections and diseases, such as Bovine spongiform encephalopathy (BSE) and Q fever in cattle. Accordingly, food and livestock feed need to be closely monitored during production, as well as during handling, processing and distribution. More processed food, more and more food imports and exports worldwide, greater movement of animal and humans have increased the distribution of global food born infection [9].

\section{Emerging and Re Emerging Pathogens}

According to [7], an emerging disease is defined as a new infection resulting from the evolution or change of an existing patho- gen or parasite resulting in a change of host range, vector, pathogen city or strain; or the occurrence of a previously unrecognized infection or disease. A re-emerging disease is considered an already known disease that either shifts its geographical setting or expands its host range, or significantly increases its prevalence. Many elements can contribute to the emergence of a new zoonotic disease: microbial/virologic determinants, such as mutation (influenza), host factors (immune system) and environmental determinants (climate, ecology for vector). Many activities involving zoonotic disease control are at risk because of a failed investigative infrastructure or financial base. Because zoonotic diseases are distinct, their prevention and control will require unique strategies [39].

\section{Human Animal Interaction}

The interaction between human and animal is not a new phenomenon. However, the scope, scale, and world-wide impacts of zoonoses we are facing today have no historical precedent. Zoonoses incidence is higher particularly in rural agricultural communities (poor society that usually live in very close contact with their animals are likely to be exposed to pathogen through direct contact or indirectly by vectors) and those who frequently have direct contact with pets (children and pregnant women), companion (tourist) and all kinds of animals during diagnosis, handling and treatment (veterinary practitioner) in urban society [40].

\section{Pathogen Host Range}

Many zoonotic pathogens fall into the category of generalist agents exhibiting extensive host diversity, example, Coxiella burnetii, the etiologic agent of Q fever. This bacterium can successfully infect hosts ranging from domestic animals to wildlife, reptiles, fish, birds, and ticks. Another example of disease which affects multiple hosts is rabies. The virus can maintain itself in wild, domestic animals and probably in vampire bats in Australia. For the reason mentioned above, pathogens that circulate in many hosts are very difficult to bring them under control [41].

\section{Prevalence of Human Immunodeficiency Virus (HIV)/ Acquired Immunodeficiency Syndrome (AIDS)}

The HIV/AIDS epidemic has also caused an additional challenge to VPH service delivery in developing countries. An estimated 42 million individuals are currently infected worldwide, with the vast majority of those in sub-Saharan Africa. HIV/AIDS is a significant cause of immune suppressant that puts infected individuals at higher risk for developing severe complications from zoonotic infections and other animal-related hazards [42]. Individuals with HIV infection that has progressed to the stage of AIDS face significant health risks from pathogens associated with animals, insects, food, and water and are more likely to develop serious illnesses from such infections than non immunocompromised people. The major key role of public health veterinarian for HIV/ AIDS patients is to educate them about zoonotic infection which 
is likely to cause complication in immunocompromised individual Pan American Health Organization Food and Agricultural Organization [43].

\section{Climate Change}

Projected climatic changes are expected to increase the risks of vector-borne and other diseases in humans and animals, such as Rift valley fever and schistosomiosis which are related to climate. Many of the potential impacts of climatic change will take years or even decades to become obvious [44].

\section{World Population}

The human population is expected to double before 2015 . The proportion of the total population of developing countries that lives in urban areas will increase from an estimated $37 \%$ in 1990 to $52 \%$ by 2020 [45]. The steadily increasing global population is responsible for a range of complex social and environmental changes. For example, the world has witnessed the global expansion of towns and cities as rural populations move into urban areas in search of work, health services, education and basic services. As a result, ecologic habitats have been disrupted which in turn results in serious health impact on both human and animal, reservoir abundance has changed, and transmission dynamics have been altered. Reduced host abundance may force vectors to seek alternative hosts, increasing opportunities for disease transmission [46].

\section{Future Trends of Veterinary Public Health}

Future employers of veterinarians working in public health see a fast-growing demand. Emerging zoonotic diseases, bio-security threats, and food-safety problems all require the expertise of veterinarians with a focus on complex, global problems that span both human and animal health. Over the past two decades, the impetus for health for all has come from primary health care. However, although some improvements have been made, progress has been hampered for several reasons; including insufficient political commitment towards implementing the necessary measures and to achieving intersects oral actions for health [1].

The role of VPH within the global health agenda will be promoting activities that contribute to the achievement of health for all and help realize its objectives. A number of global changes will occur during the next 25-30 years that will have a dramatic impact on most professional groups, especially physicians and veterinarians. The daily interactions of humans, animals, and the environment have a dramatic impact on public health. Current and evolving health threats include infections transmitted through animals, insects, food, and water, as well as illnesses resulting from environmental toxins, the misuse of antibiotics, and bioterrorism. Factors affecting these threats include the international movement of people, animals, and animal products; globalization and management of the complex food and fiber system; climate and other environmental changes [47], including those affecting wildlife populations and their interactions; and national and global security. Effectively meeting these challenges requires strong links between human and animal health clinicians, researchers, laboratories, and public health officials [48].

\section{Conclusion and Recommendations}

Although the activity of VPH varies among different countries, its scope is multidisciplinary. In developing countries, economic, social and cultural constraints and perceptions may present obstacles to the establishment of effective and a committed VPH staffs. As a result, the delivery of VPH services in developing countries in particular calls for an interdisciplinary approach. VPH will continue to develop against a rapidly changing background of population growth, increasing urbanization an increasing poverty and technology gap between developed and developing countries, and changes in land use, the environment and the climate. Therefore, in line with the above views the following points are recommended:

To maintain effective VPH program, there must be defined VPH structure at both national and international level. International organizations such as FAO, OIE and WHO assistance in harmonizing surveillance systems, facilitating agreement on the types of data that should be shared internationally, and assuring quality control for surveillance data should be encouraged. Very close collaboration between Public Health and Veterinary Medicine professionals is crucial to attain optimum public health.

\section{Acknowledgment}

Special thanks to Dr. Alemayehu Lemma and staffs of College of Veterinary Medicine and Agriculture, Addis Ababa University.

\section{References}

1. WHO (2002) Future Trend in Veterinary Public Health: A report of WHO study group (Technical Report Series, No 907) Geneva.

2. Kakkar M, Syed Shahid A, Ashok K, Mohammad AH, Kavya S (2013) Veterinary public health capacity building in India: a grim reflection of the developing world's under preparedness to address zoonotic risks, WHO. S-E. Asia. J. Pub. Health 2: 3-4.

3. Lonnie K, Rima K (2003) Converging Issues in Veterinary and Public Health. Emerg. Infect. Dis 9: 510-511.

4. Malinda $L$ (2011) Veterinary profession has long protected animal and public health. Symposium underscores achievements over the year. J. Am. Vet. Med. Assoc 15: 3-5.

5. Steele JH (1978) Veterinary public health: early history and recent world developments. J. Am. Vet. Med. Assoc 173: 1493.

6. Kahn LH, Kaplan B, Steele JH (2007) Confronting zoonoses through closer collaboration between medicine and veterinary medicine (as 'one medicine'). Vet. Italian 43: 5-19. 
Citation: Kaba T, Zerihun T, Abera B, Kassa T (2017) A Review on the Role of Veterinary Public Health and Its Current Challenges. Arch Vet Sci, 2017 : VST-114.

7. OIE (2013) World organization for animal health: Emerging and re emerging zoonoses.

8. Kouba V (1992) Veterinary public health in worldwide animal health and production. Rev. Sci. Tech. off. Epiz 11: 241-254.

9. WHO (2006) the control of neglected zoonotic disease: route to poverty alleviation. Report of a Joint WHO/DFID-AHP Meeting with the participation of FAO and OIE Geneva.

10. Forget G, Lebel J (2001) Ecosystem approach to human health. Int. J. Occup. Environ. Health 7: 3-5.

11. Belino ED (1992) Organization of veterinary public health in Africa. Rev. Sci. Tech. Off. Int. Epiz 11: 99-116.

12. Brückner GK (2014) A brief overview of the history of veterinary field services in South Africa. J. South. Afri. Vet. Assoc 85: 7-15.

13. Girma S, Zewde G, Tafess K, Jibat T (2012) Assessment of awareness on food born zoonosis and its relation with veterinary public health service in and around Addis Abeba. Ethio. Vet. J 16: 15-22.

14. Tuchili LM (1988) Epidemiology, prevention and control of rabies and brucellosis in Zambia. In: Proceedings of the international conference on epidemiology, control and prevention of rabies and brucellosis in Eastern and Southern African countries, Gaborone, Botswana. Marcel M. (ed) 23-25.

15. Laura HK (2006) Confronting Zoonoses, Linking Human and Veterinary Medicine. Emerg. Infect. Dis 12: 556-561.

16. Hoblet K, McCabe A, Heider L (2003) Veterinarians in population health and public practice: meeting critical national needs. J. Vet. Med. Educ 30: 287.

17. Marguerite $P(2006)$ Veterinarians in public health: assuring the conditions in which people can be healthy. Leadership in Public. Health 7: 29-30.

18. Peter JC (2000) Veterinary education, zoonoses and public health: personal perspective. Atropica. Facu. Vet. Sci. Univ. Liver 76: 77-80.

19. Schwabe CW (1968) Animal diseases and world health. J. Ame. Vet. Med. Assoc 153: 1859-1863.

20. Mantovani A (1992) Zoonoses control and veterinary public health. Rev. Sci. Tech. Off. Int. Epiz 11: 205-218.

21. Bennett M, Begon M (1997) Virus zoonoses a long term overview. Comp. Immunol. Microb. Infect. Dis 20: 101-109.

22. Hahn B, Shaw G, De Cock K, Sharp P (2000) AIDS as a zoonosis: scientific and public health implications. Sci 287: 607.

23. Walsh D, Murphy F, Osburn B, King L, Kelly A (2003) an agenda for action: veterinary medicine's crucial role in public health and biodefense and the obligation of academic veterinary medicine to respond. J. Vet. Med. Educ 30:92-95.

24. FVE (2013) Meat Inspection and the Development of Community Risk Based Food Legislation.

25. Maccabe AT, Matchett KE, Hueston WD (2008) The Need for PublicHealth Veterinarians as Seen by Future Employers: Additional Perspectives in Veterinary Public Health Education. J. Vet. Med 35: 274-278.

26. Nafisa H, Amber F, Adnan K, Ameera Y, Shahana U (2010) Microbial contamination of raw meat and its environment in retail shops in Karachi, Pakistan. J. Infect. Dev. Ctries 4: 382-388.
27. Lunden J, Bjorkroth J, Korkeala H (2007) Meat inspection education in Finnish veterinary curriculum. J. Vet. Med. Educ 34: 205-2011.

28. Elroy M (2002) Benefit of linking public health, animal health and food safety surveillance. Can. Vet. J 43: 796-97.

29. Bousfield B, Brown R (2011) the veterinarian's role in food safety. Vet. Bull. Agri. Fish. Conserve. Dept 1: 6-10.

30. Smith DF (2013) Lesson of history in veterinary medicine. J. Vet. Med. Edu 40: 2-11

31. Denis GA (2002) the farm to plate approach to food safety-everyone's business. Can. J. Infect. Dis 13: 185-90.

32. Nielsen NO (1992) Ecosystem health and veterinary medicine. Can. Vet. J 1: 23-26.

33. de Moissac JE (2009) Veterinarians in public health, Challenges and opportunities. Can. Vet. J 50: 897-98.

34. Zinasstage J, Schelling E, Waltner-Toews D, Tanner M (2011) from one medicine to one health. Prev. Vet. Med 101: 148-156.

35. Diane F (2008) one world, one health one medicine. Can. Vet. J 49: 1063-1065.

36. Jennifer $F$ (2011) Great challenge facing veterinary profession. The. Vin. News. Serv 4: 11-12.

37. OIE (2007) Terrestrial animal health code, 2007 edition. OIE, Paris, France.

38. Crawford LM (1985) the impact of residues on animal food products and human health. Rev. Sci. Tech. Int. Epiz 4: 669-685.

39. Mckenzie AI, Hathaway SC (2006) the role and functionality of Veterinary Services in food safety throughout the food chain. Rev. Sci. Tech. Off. Int. Epiz 25: 837-848.

40. Frederick AM (1998) Emerging Zoonoses, Zoonotic and Vector-borne Issue. ICEID, Univ. Calif. USA 4: 33-35.

41. Lappin MR (2005) General concepts in zoonotic disease control. Vet. Clin. North. Am. Small. Anim. Pract 35: 1-20.

42. Cleaveland S, Laurenson M, Taylor L (2001) Disease of human and their domestic mammals, phatogen charecterstics, host range and risk of emergence. Phil. Trans. R. Soc. London 356: 991-999.

43. Radford GD (2008) HIVIAIDS Education: Still an important issue for vets. Public. Health. J 123: 266-275.

44. FAO (2004) HIV infections and zoonoses. 163 ed, Viale delle Terme di Caracalla, 00100 Rome Italy.

45. Delgado C, Rosegrant M, Steinfeld H, Ehui S, Courbois C (1999) Livestock to 2020, the next food revolution. Food, agriculture, and the environment discussion paper 28. Washington, D.C. Food. Policy. Res. Inst 20: 3-7.

46. John MD (2005) Population effect of increased climate variation. Proc. Bio. Sci 272: 1823-1827.

47. Carol P (2009) Climate changes. Environ. Health. Perspec 117: 23-24.

48. Charles LW (2009) Managing agriculture in a climate change. Agr. Indu. Biol. Tech 57: 10-13.

49. Stephen M (1999) Future trend in VPH, Weekly Epidemiological Records. Int. Vet. Public. Health. Consortium 19: 88-90. 